\title{
Designing health promoting lifestyle educational content using photovoice qualitative approach in pre-diabetic people: A community-based participatory research
}

\author{
Majed Meripour ${ }^{1}$, Morteza Khafaie ${ }^{1}$, Hashem mohamadian ${ }^{1 *}$ \\ 1. Health Faculty, Ahvaz Jundishapur University of Medical Sciences, Ahvaz, Iran
}

Received: 24 February 2020

Accepted for publication: 15 November 2020

[EPub a head of print-10 January 2021]

Payesh: 2021; 20 (1):49-57

\begin{abstract}
Objective (s): Diabetes and its chronic complications is one of the major public health issues worldwide. The present study aimed to use photovoice in pre-diabetic people to design health promoting lifestyle educational content. :.

Methods: This community-based participatory research was performed on 40 pre-diabetic participants in Hoveizeh health centers, Khozestan Province, Iran in 2018. Photovoice was used to better understand pre-diabetic adults about their experiences. Focus groups and semi-structured interviews were used for data collection. All data were recorded and analyzed through content analysis based on narratives.

Results: Data analysis revealed four main themes including daily living needs ,neglect of the disease ,education and provision of health care, lack of support to adapt physical environment.

Conclusion: In designing educational content, it is necessary to place more emphasis on the four main themes extracted from the experiences of pre-diabetic people in order to provide more comprehensive services by health care personnel.
\end{abstract}

Key Words: Pre-diabetic, Narrative analysis, Photovoice, Community-based participatory research

\footnotetext{
* Corresponding author: Health Faculty, Ahvaz Jundishapur Uviversity of Medical Sciences

E-mail: hmohamadian@razi.tums.ac.ir
} 


\title{
طراحى محتواى آموزشى سبك زندكى مروج سلامت با استفاده از، عكس ـ كثتار، در افراد بيش ديابتى با رويكرد كيفى: يك يُوره مشار كتى اجتماع محور
}

\author{
ماجد مرى بور'، مر تضى خفايى'، هاشم محمديان \\ ا. دانشكده بهداشت، دانشعاه علوم يزشكى جندى شايور اهواز، اهواز، ايران

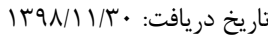

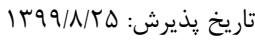

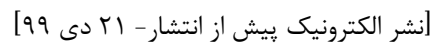

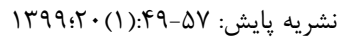

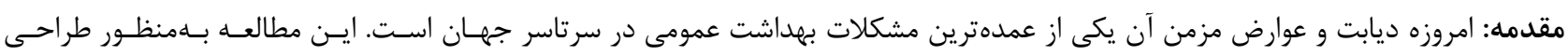

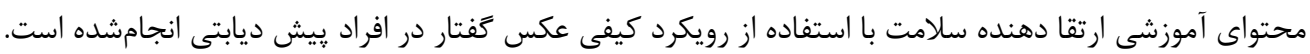

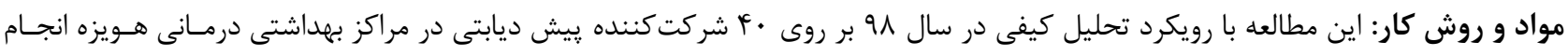

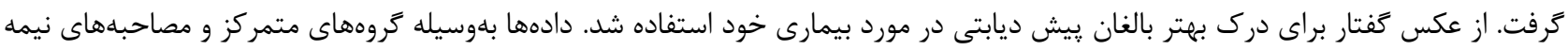

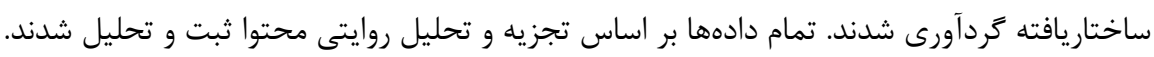

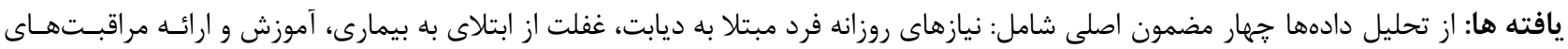

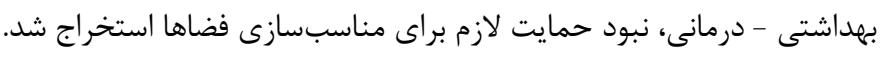

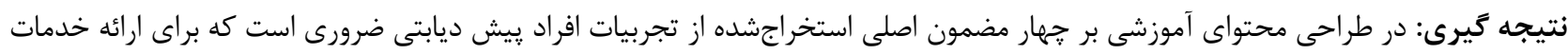

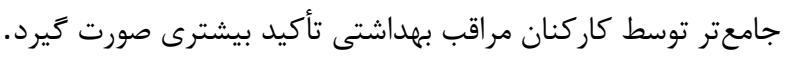

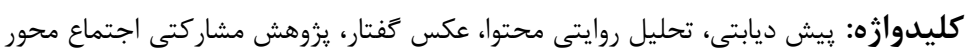

كد كار آزمايع بالينى:IRCT20171226038083N1 كد اخلاق: IR.AJUMS.REC.1397.689 


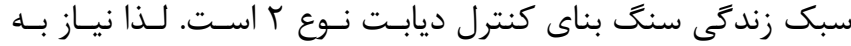

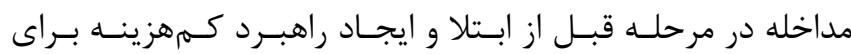

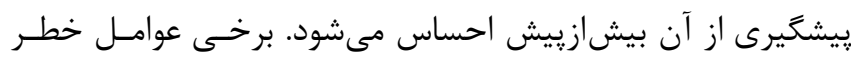

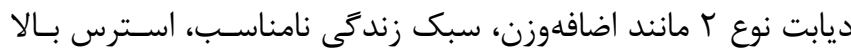

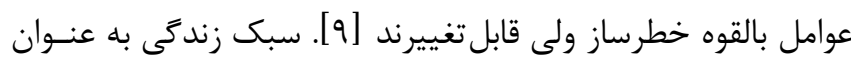

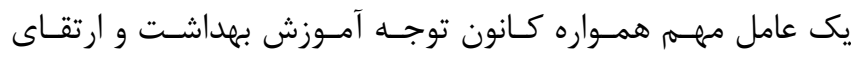

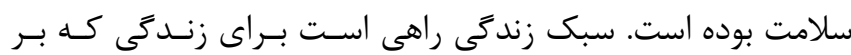

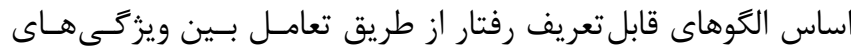

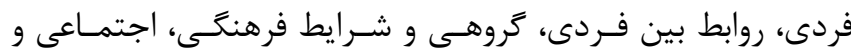

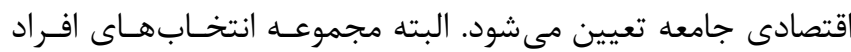

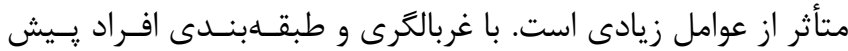

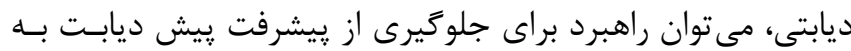

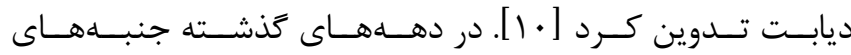
روانشناختى ديابت نظر بسيارى از متخصصان را به خود جلب كرده

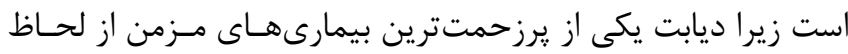

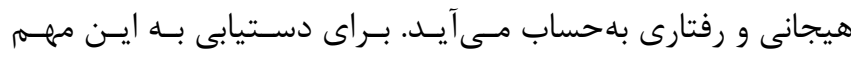

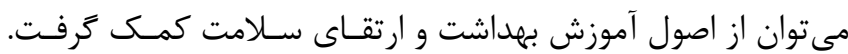

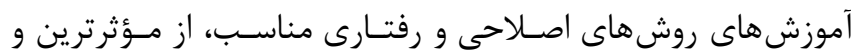
باصرفهترين راههاى بيشغيرى و كنترل ديابت محسـوب مسىشـوند.

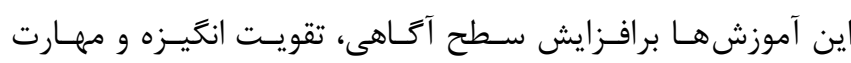

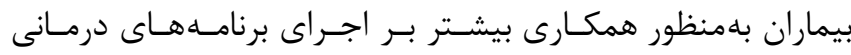

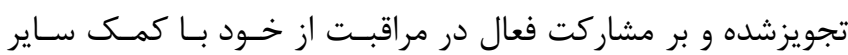

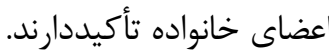
عكس كَفتار (Photovoice)، اولين بار در اوايـل دهـــ • 199 بــراى توصيف عكاسى روايتى در رابطه با كشف مسائل اجتمـاعى اسـتفاده

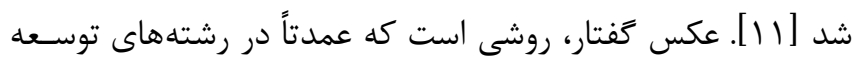

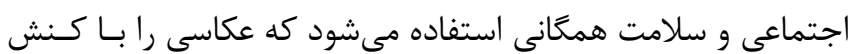

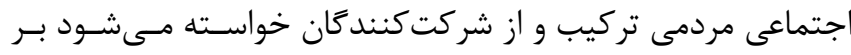

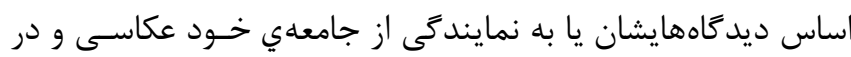

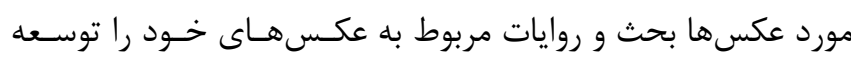
دهند. عكس كفتتار، يك روش ارزيـابى مشـاركتى اسـت كـهـ توســ

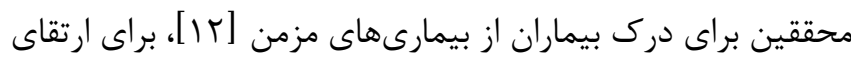

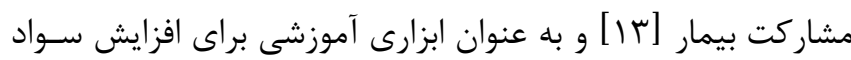

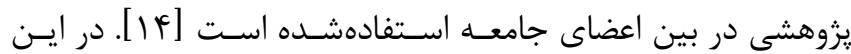
روش، شركت كنندكان از عناصر معنى دار در محسيط خـود، از قبيـل

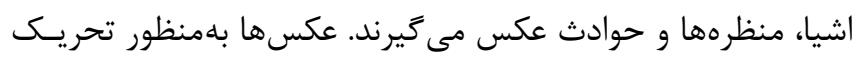

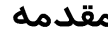

امروزه، ديابت و عوارض مزمن آن به علت بِيشـرفتهـاى اقتصـادى،

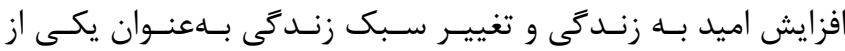

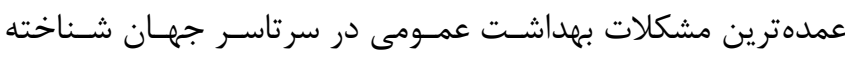
شده است. ديابت، جزو بيمارىهاى مزمنى است كه به دليل اختلال

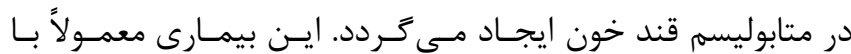

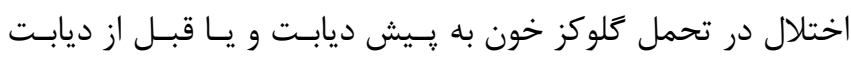

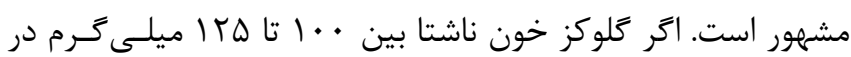

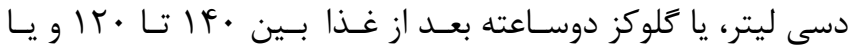

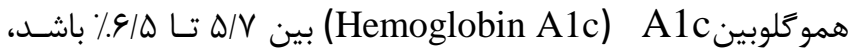

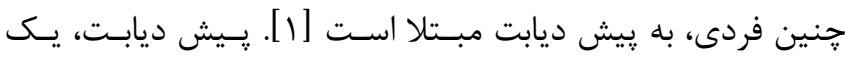
حالت متوسط قند خون با سطح كلوكز بالاتر از حالـت طبيعى امـا زير سطح تشخيصى ديابت تعريف مى شود. شـيوع يـيش ديابـت در

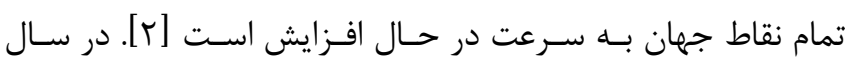

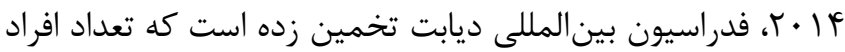

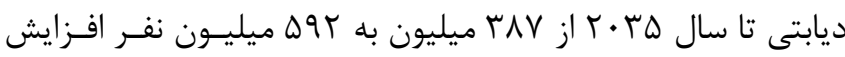

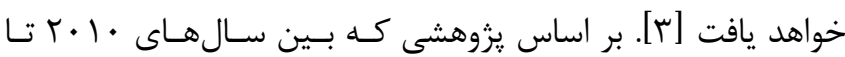

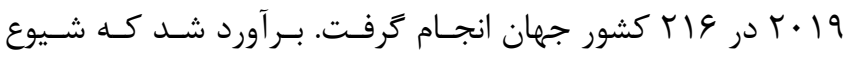

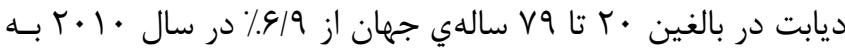

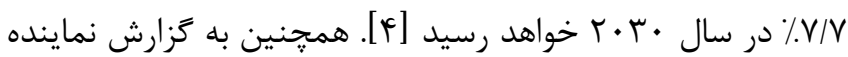

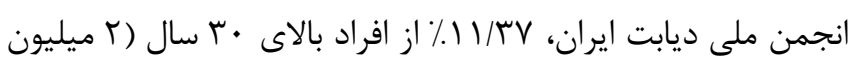

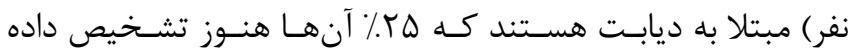

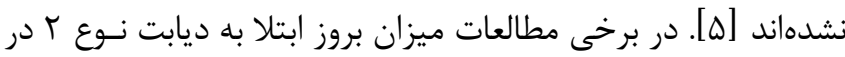

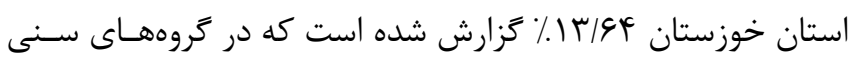

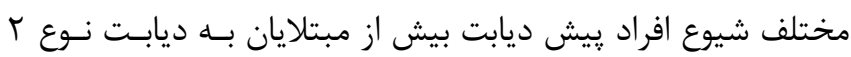

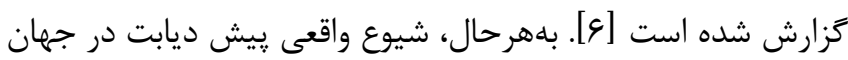

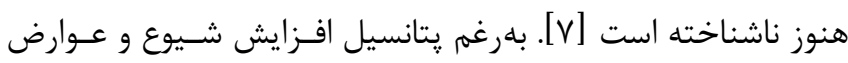

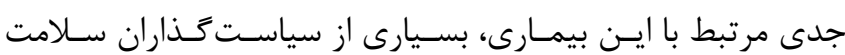

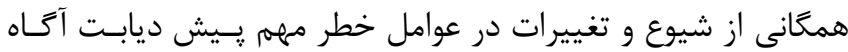

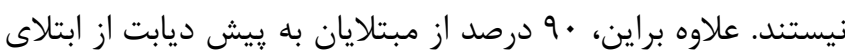

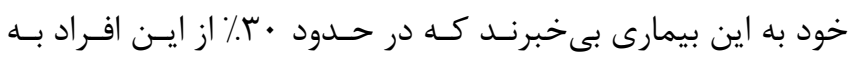

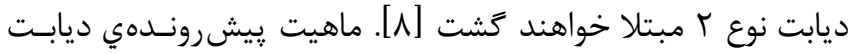

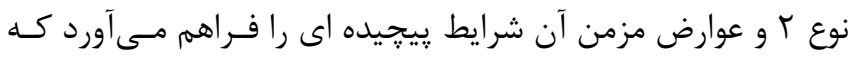

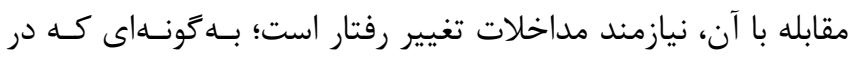

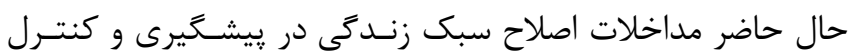

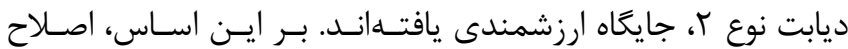


بركزار شد و تقريباً س ساعت ادامه داشت. از شركت كنندكان خواسته شد كه از افراد قابلشناسايى در عكس رضايتنامه اخذ كنند.

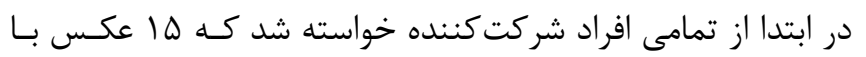

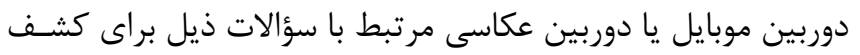

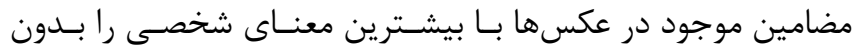
كمك گروه تحقيقاتى بخيرند.

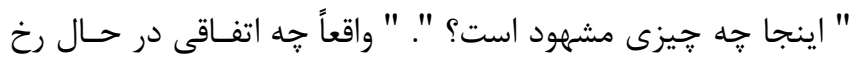

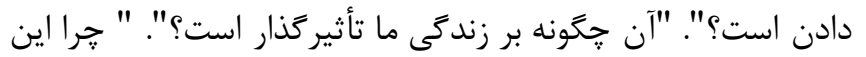

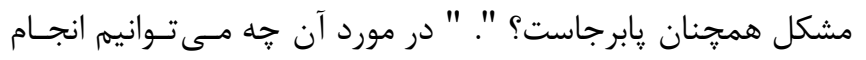

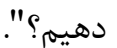

سيس در يك جلسه بحث گَروهى از آنها خواسته شـد از بـين ها

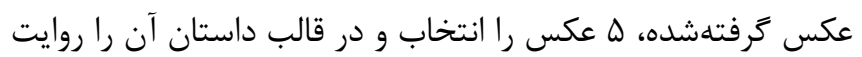

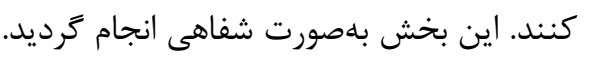

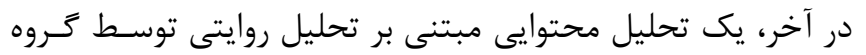

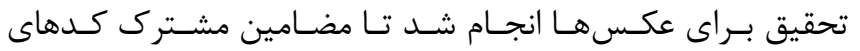

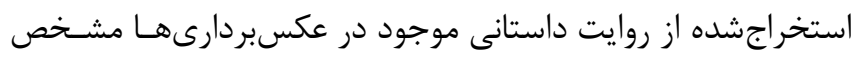

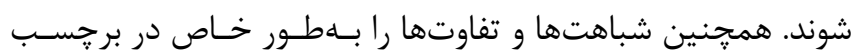

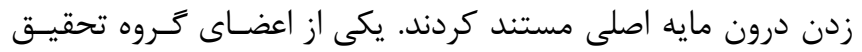

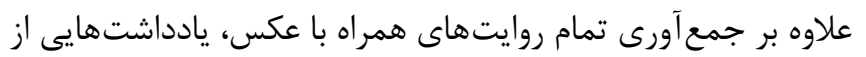

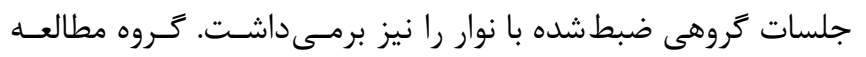

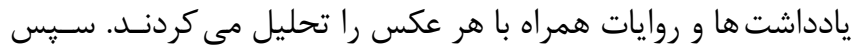

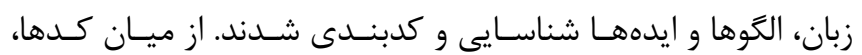

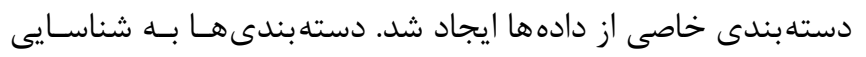

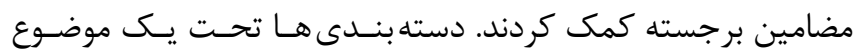

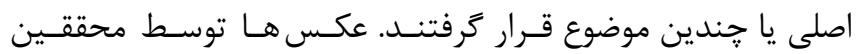

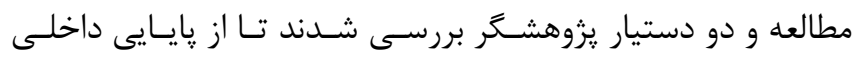

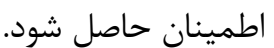

\section{يافتهها}

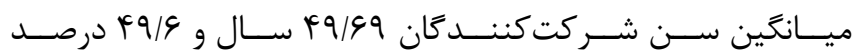

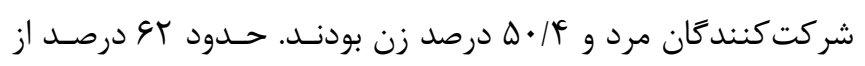
افراد مطالعه بـىسواد بودند.

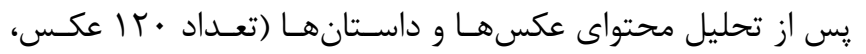

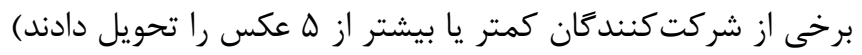

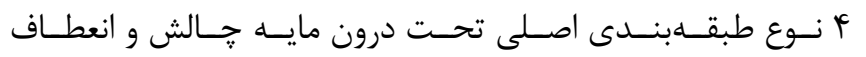
استخراج شد. (Challenge and Resilience)
كفتكو و ايجاد يك يلتفرم مشخص جهت به اشتراك كذاشتن روايت

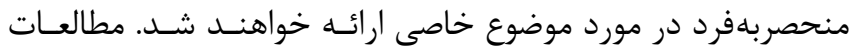

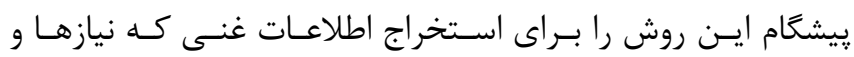

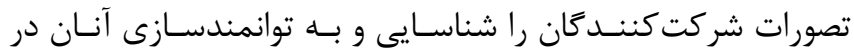

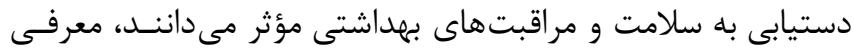

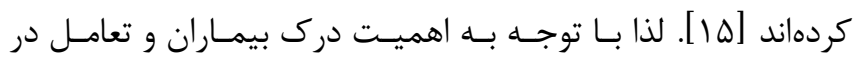
مراقبت و توجه به بيمار، استفاده از عكس كفتتار مىتواند براى درى

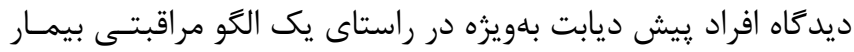

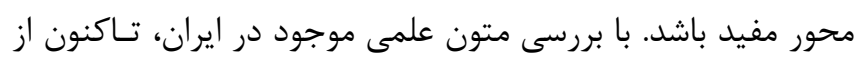
عكس تفتار براى كشف عوامل مؤثر جهت طراحى محتواى آموزشى دانى

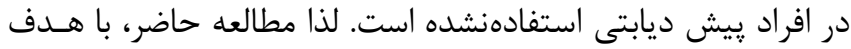

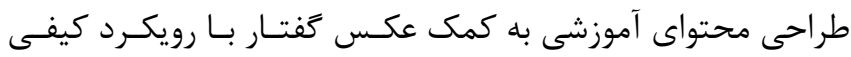

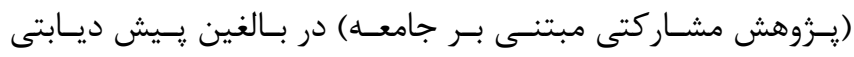
شهرستان هويزه انجامشده است.

\section{مواد و روش كار}

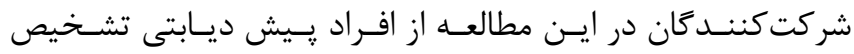
دادهشده در مركز مطالعاتى كو هورت هويزه به روش تصادفى سـاده

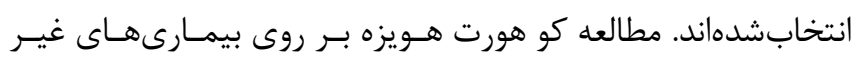

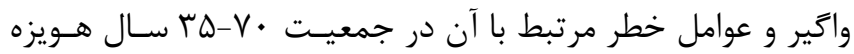

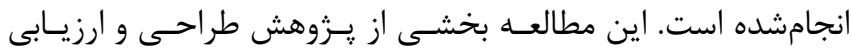

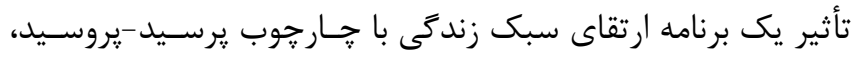

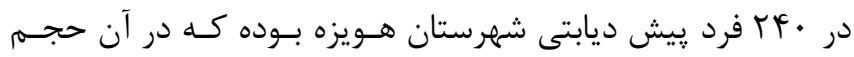

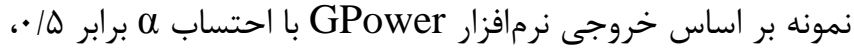

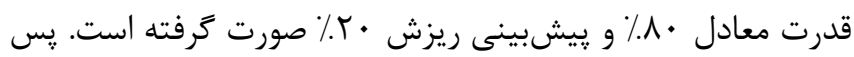

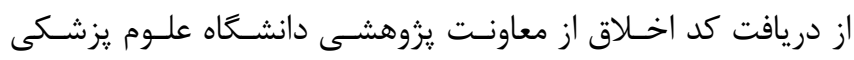

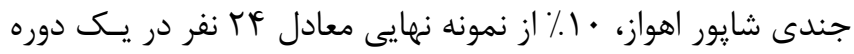

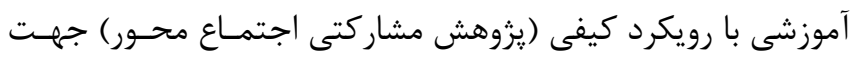

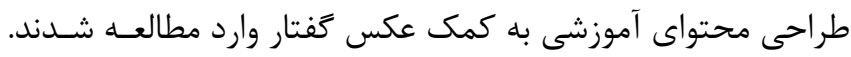

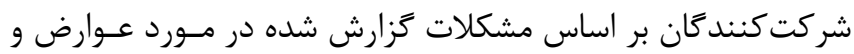

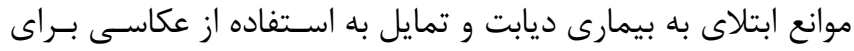

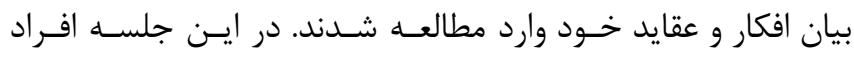

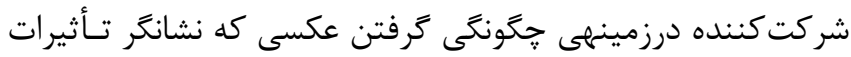

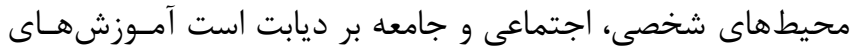

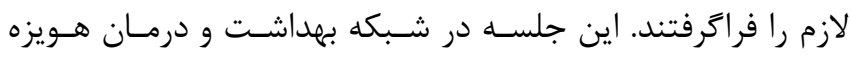


افراد ديابتى در نهايت مى تواند باعث آسيب بـهـ اعصـاب بـــن شـود.

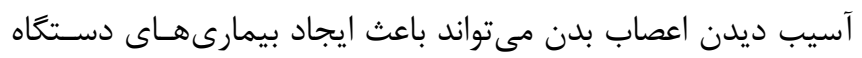

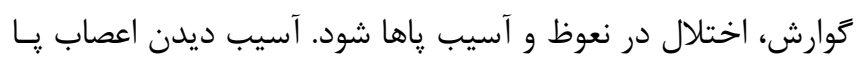

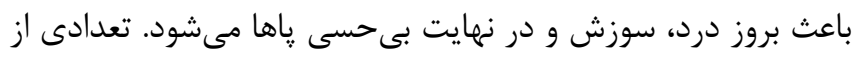

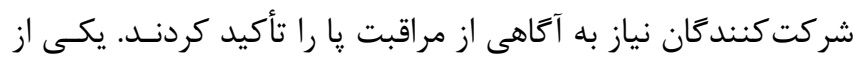

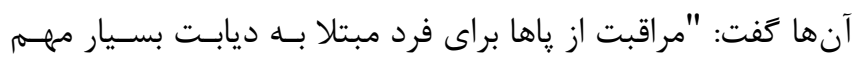

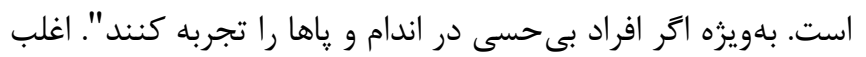

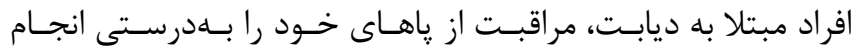

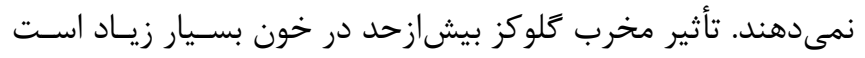

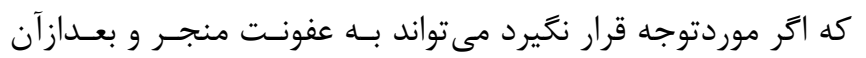

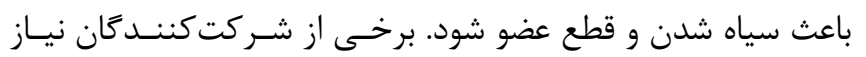

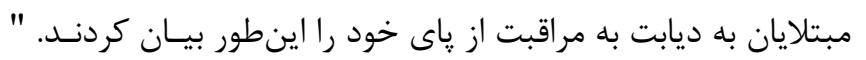

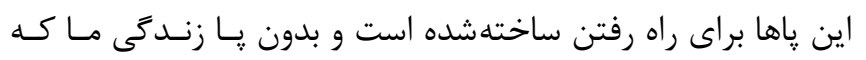
كشاورز و دامدار هستيم فلج مىشود " (شكل r r).

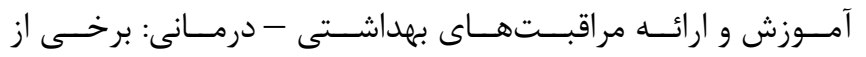

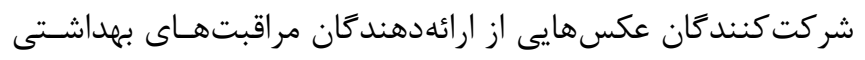

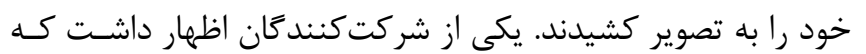

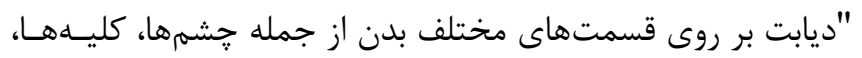

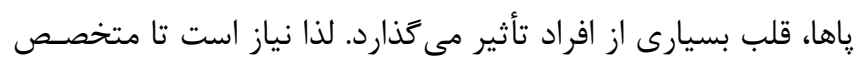

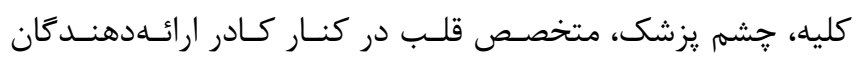

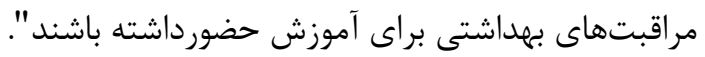

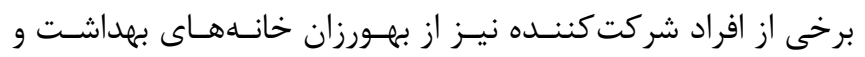

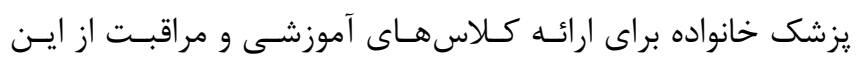

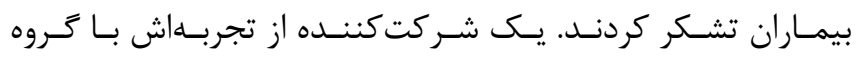

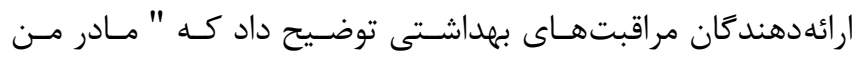

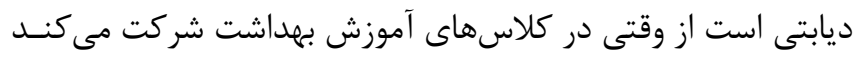

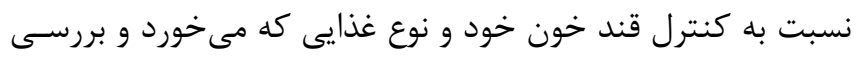

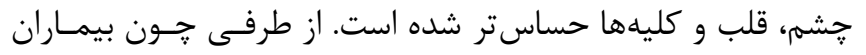

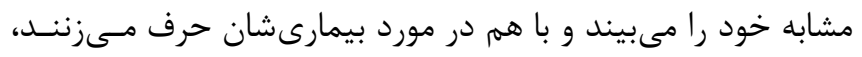

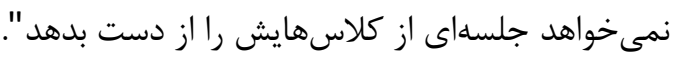

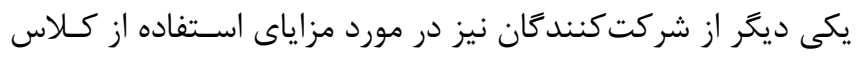

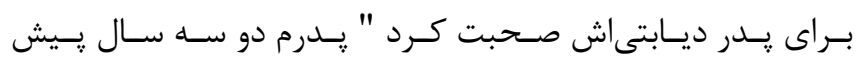

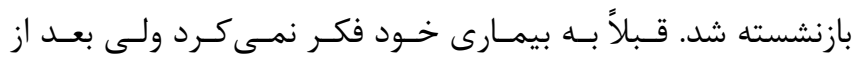

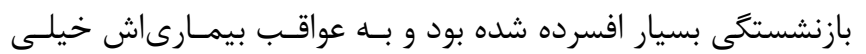

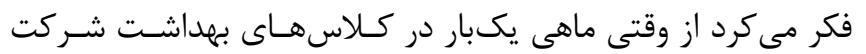

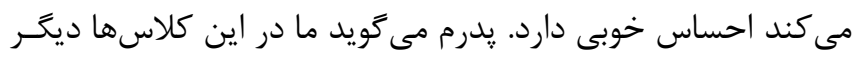

عكسها و داستانها به درون مايه هاى نيازهاى روزانه فرد مبتلا بـهـ

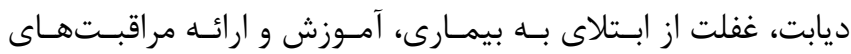

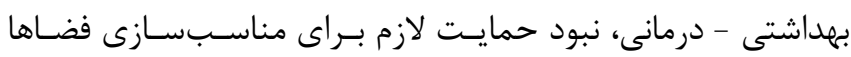

طبقهبندى شدند.

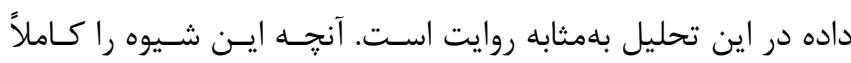

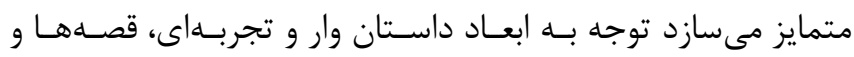
حكايتهاى شخصى است كه راوى در زنجيرهاى منظمه نقل مى كند.

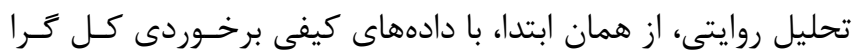

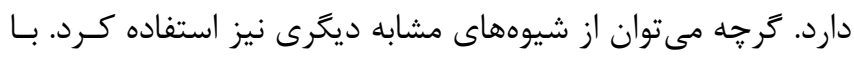

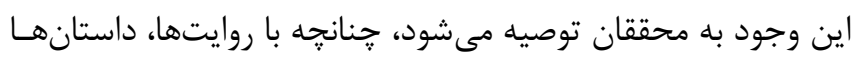

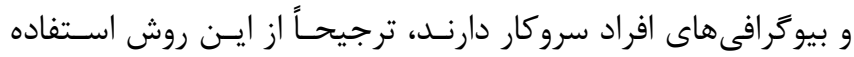

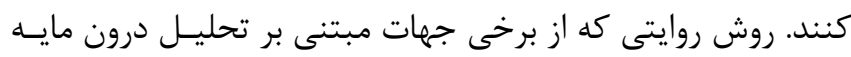

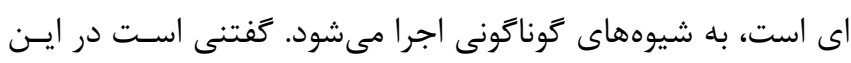

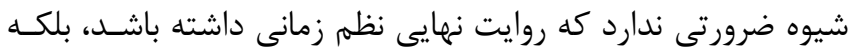

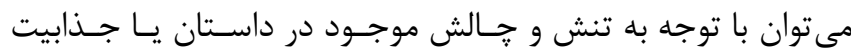

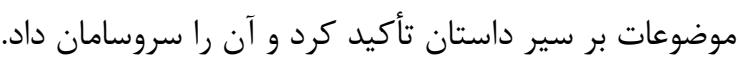

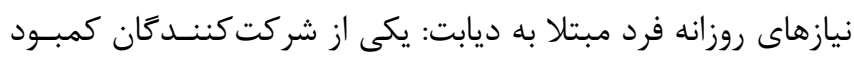

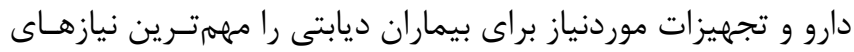

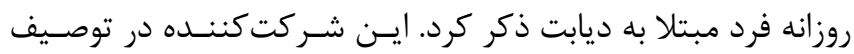

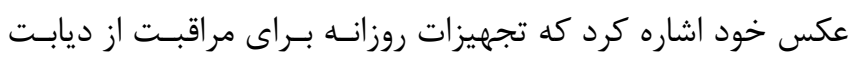

موردنياز است (شكل ()). يرداخت هزينه براى نيازهاى بزشكى آنها ها (به عنوان مثال نوار، دارو

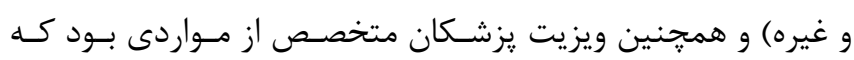

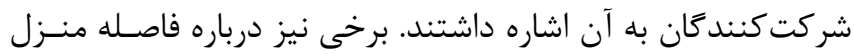

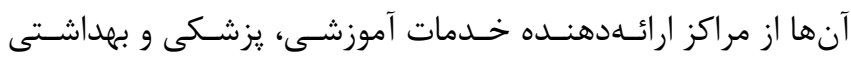
صحبت مى كردند. غفلت از ابتلاى به بيمـارى: برخـى از شـركت كنــــــان در مر مطالعـهـ

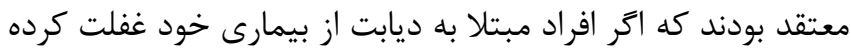

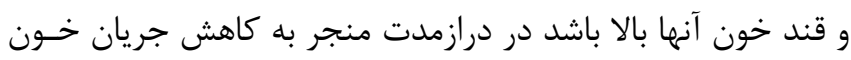

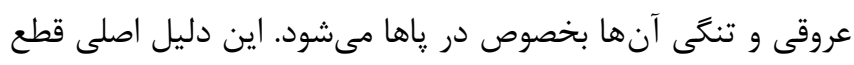

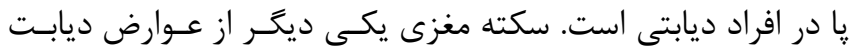

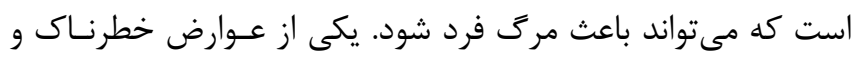

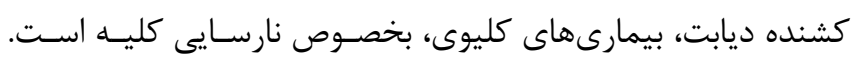

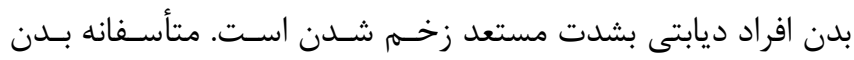

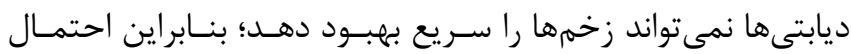

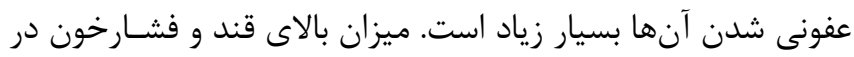


مناسب، مسيرهاى آسفالت نشده در برخى نقاط شهر و روستا و عدم

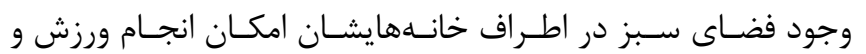

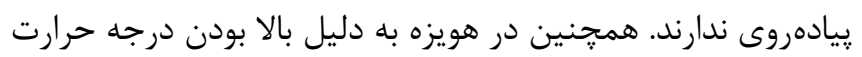
هوا امكان ورزش كردن در محيطهاى باز وجود ندارد.

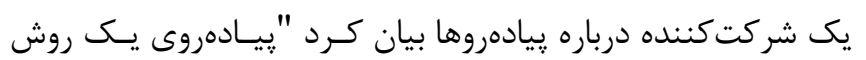

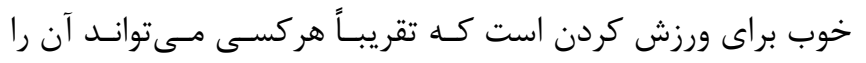

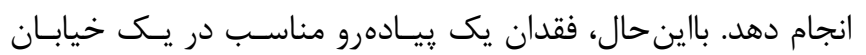

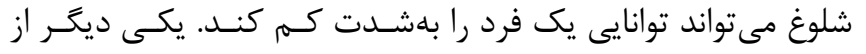

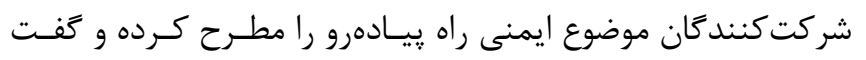

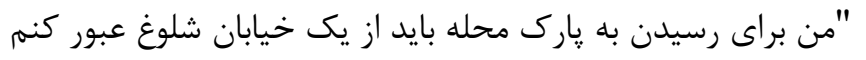
كه ماشين ها با سرعت عبورمى كنـــد و مسن جشـمهم ضـعيف اسـت

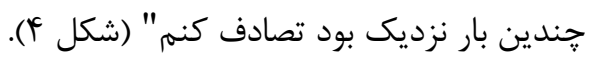

افراد مبتلا به ديابت را مىبينيهم. ما همه نظـرات خودمـان را مطـرح

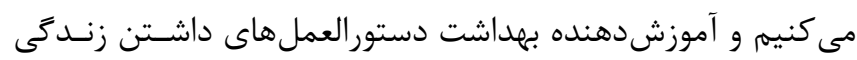

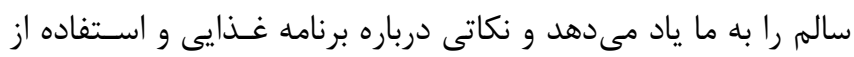

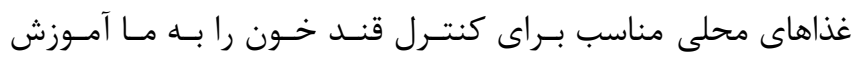

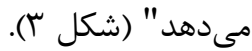
نبود حمايت لازم براى مناسبسازى فضاهاى شـهرى يـا روسـتايى:

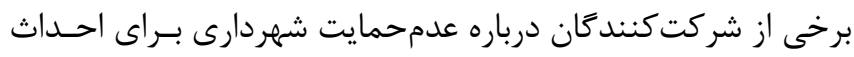

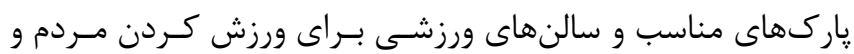

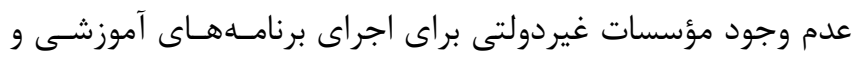
حمايت اجتماعى در شهرستان هويزه صحبت كردند.

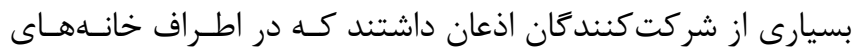

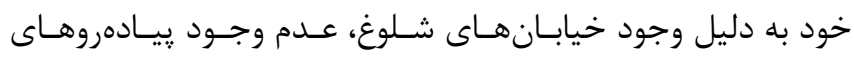

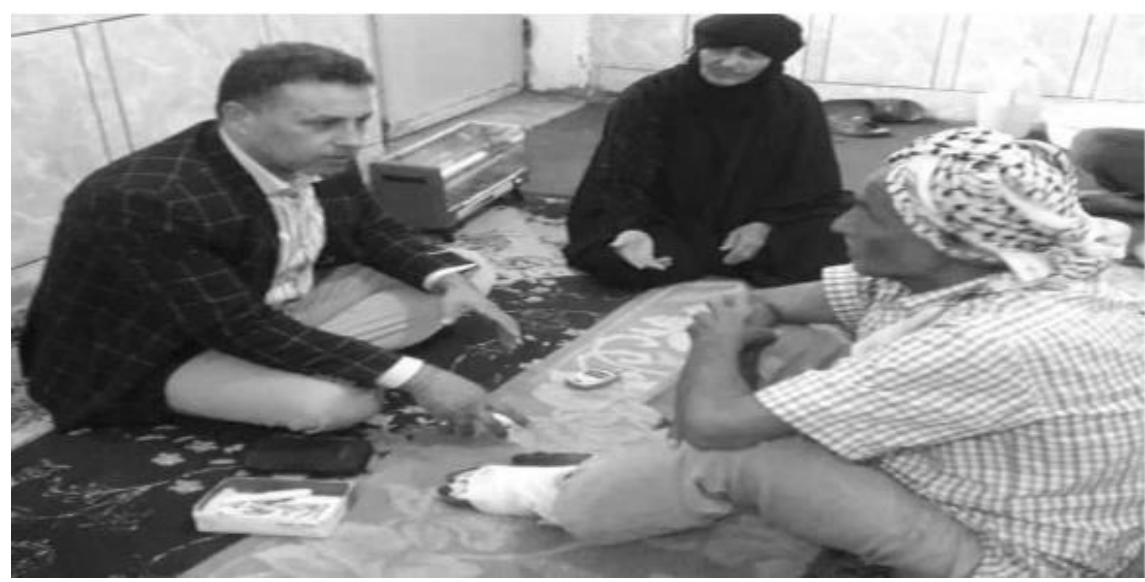

شكل ا: كمبود دارو و تجهيزات، جالش بزرى ديابتىها

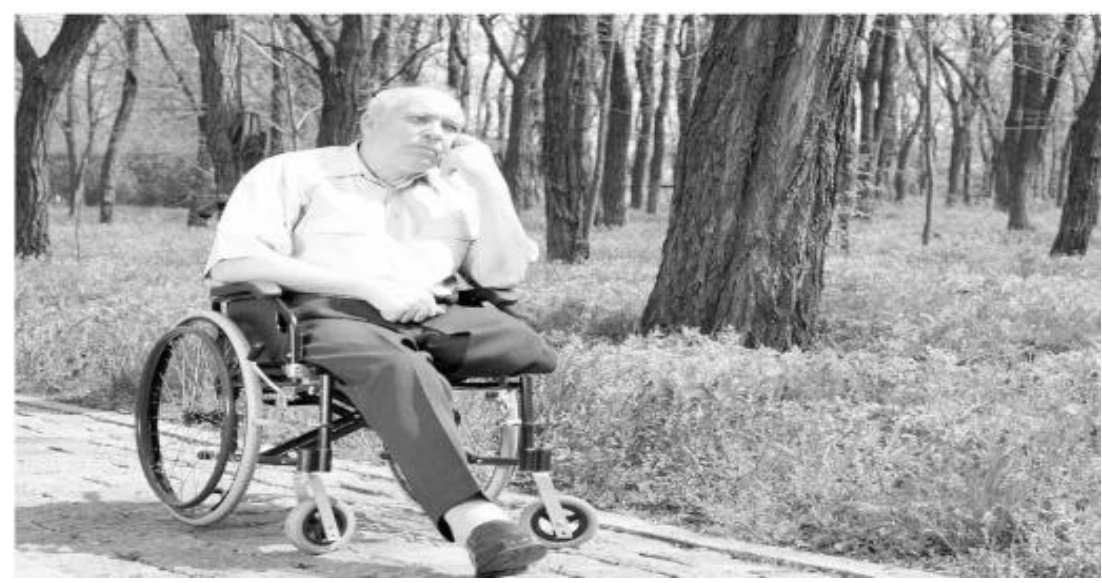

شكل r: غفلت از ابتلاى به بيمارى 


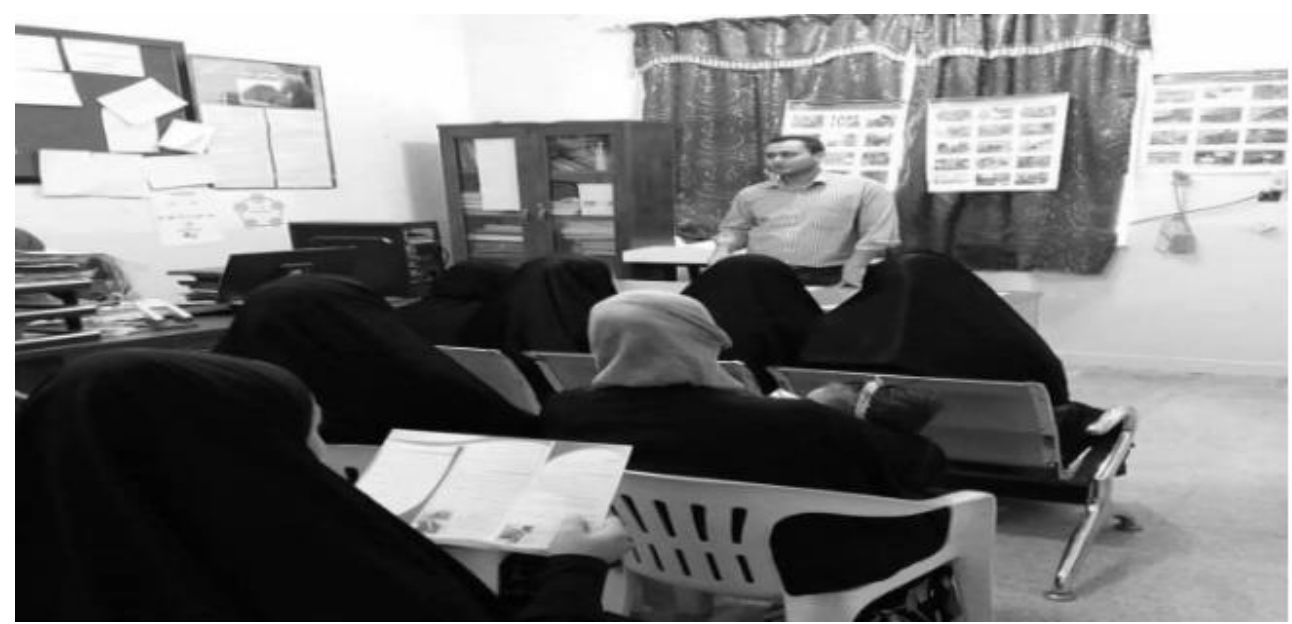

شكل r: آموزش و ارائه مراقبتهاى بهداشتى - درمانى

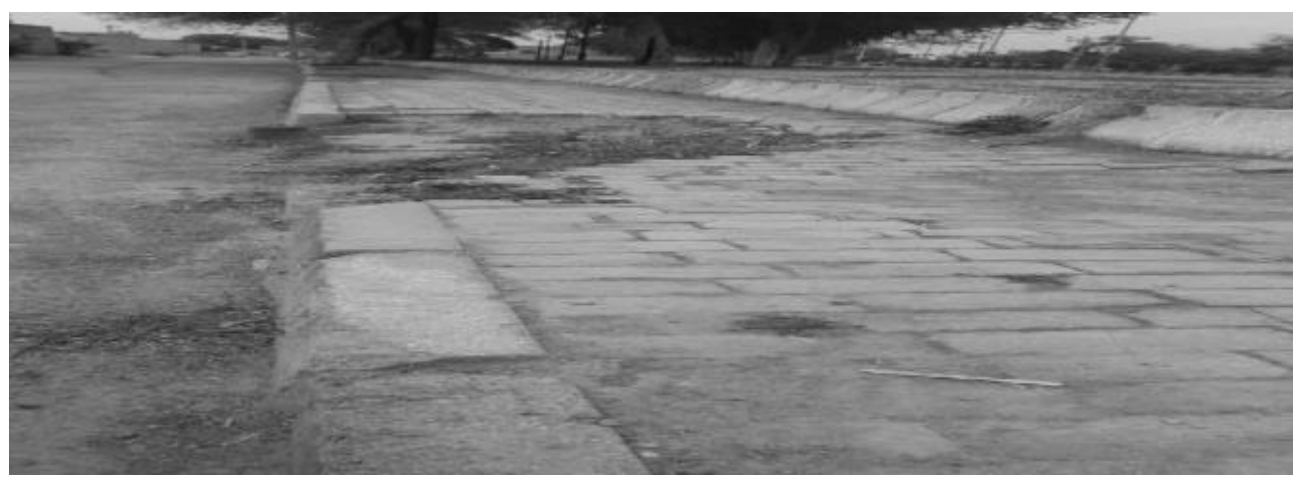

شكل F: عدمحمايت كافى براى مناسبسازى فضاهاى شهرى يا روستايى

يزوهشكر نسبت به آنجه براى شركت كنند

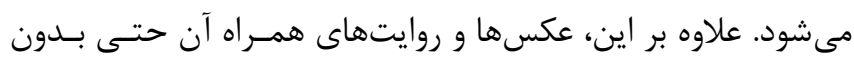

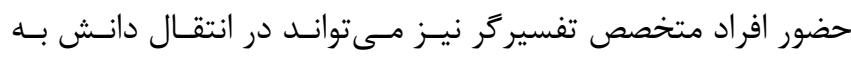

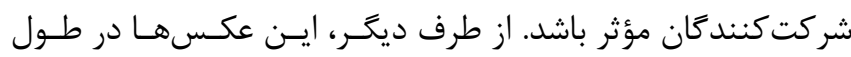

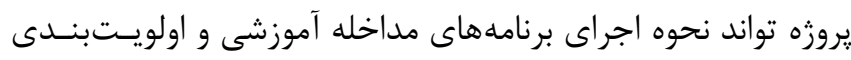

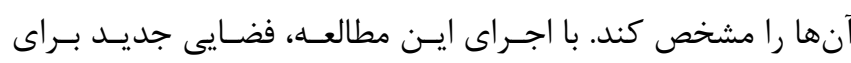

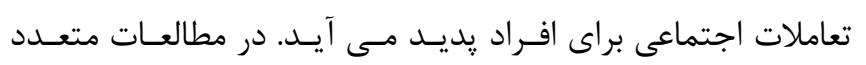

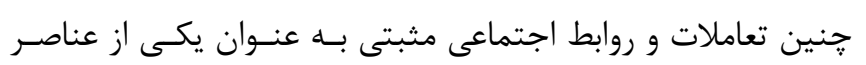

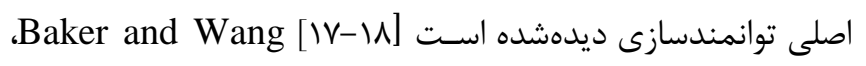

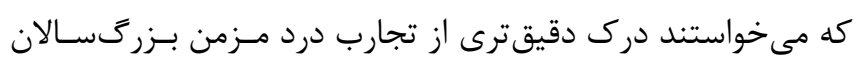

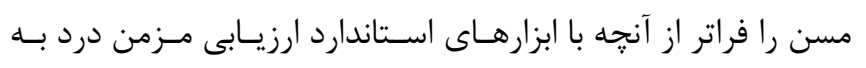

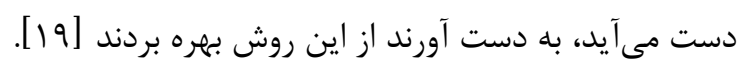

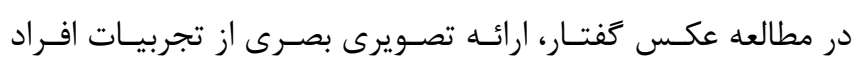

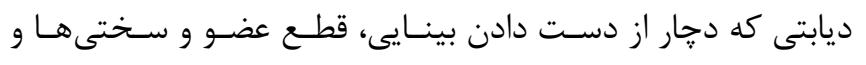

\section{بحث و نتيجه ثيرى}

روش عكس كفتار به دليل توانايى اثباتشده آن در نيازسـنجى، بـهـ

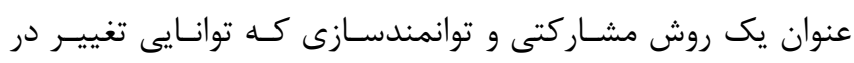
خطمشى و سياستها در سطح فردى، اجتمـاعى و عمـومى را دارد،

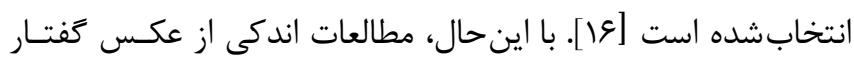
به عنوان بخشى فعال از مداخلات مديريت بيمارى استفاده كردهاند.

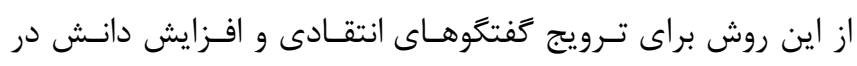

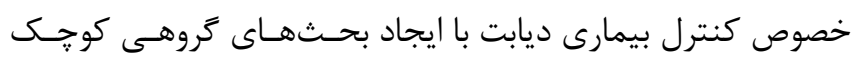

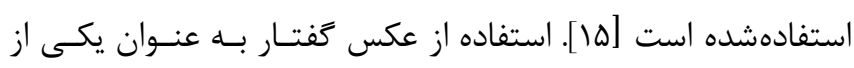
مؤلفه هاى مطالعهي كيفى، نه تنها توانايى ارزيابى نيازهاى جامعـهـ در

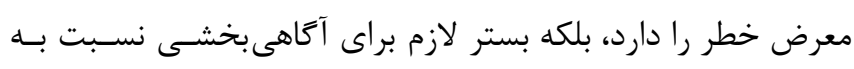

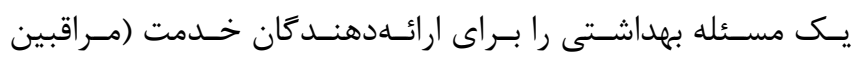

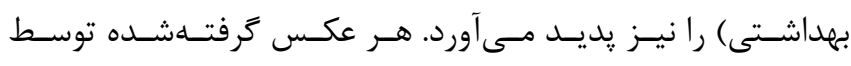

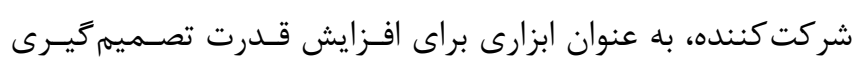


يكى از نقاط قوت اين مطالعه رامى توان اين كونه بيان داشـت كـهـ

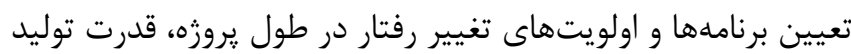

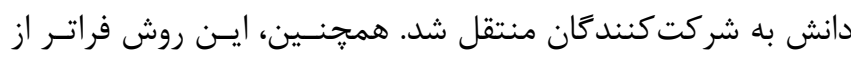
آنجه در تحقيقات بِيمايشى انجام مىشود، به نيازسنجى جامع تـرى دستيافت. يكى از محدوديتهاى مطالعه حاضر اين بود كه در كر بروه

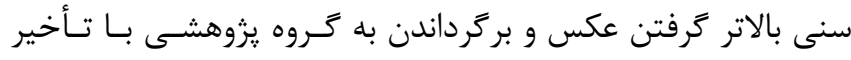

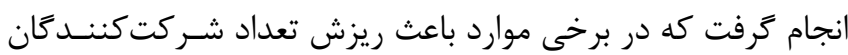

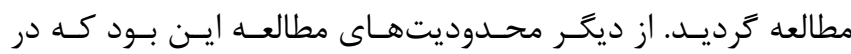

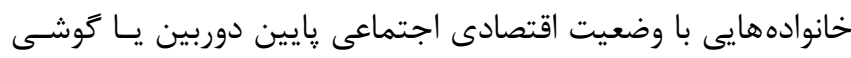

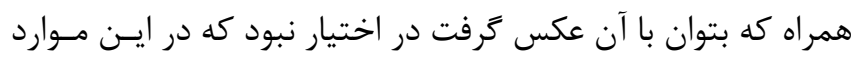

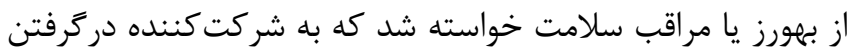

$$
\text { و ارسال عكس كمك كنند. }
$$

با اجراى صحيح روش عكس كَفتار، صداى شركت كنندكان بيرامـون

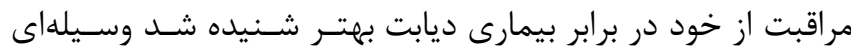

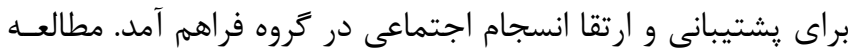

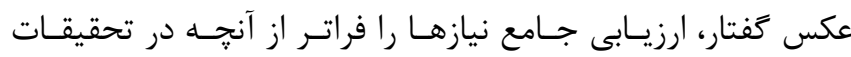

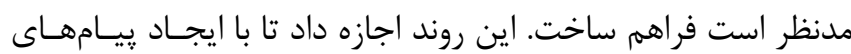

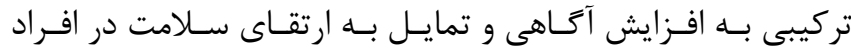
دست يابيهم. اين روش براى جوامعى كه با موانـع بهداشـتى مشـابهى

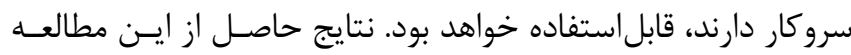
در يياده سازى خطمشى هاى مقتضى با شناسايى نيازها و منابع لازم

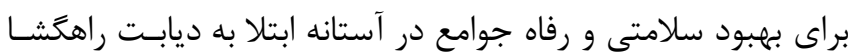

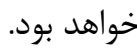

\section{سمه نويسند كَان}

ماجد مرى يور: جمع آورى داده، كمك در نحــارش يايـان نامـهـ و تـدوين

مقاله مرتضى خفايى: مشاوره علمى و كمك در تجزيه و تحليـل و نكـارش يايان نامه هاشم محمديان: طراح پاياننامه، تجزيه و تحليل و ننارش پاياننامه و كمك به تدوين مقاله

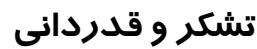

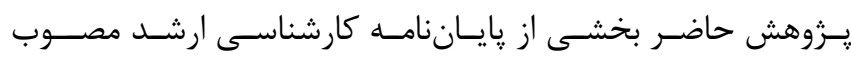

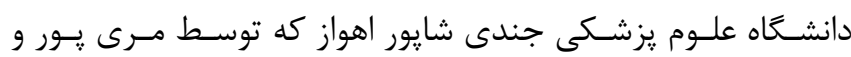

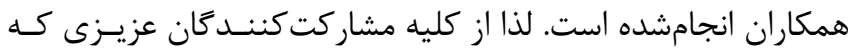
در ايـن يزوهش صميمانه همكارى كردند تقدير و تشكرمى شود.
جالشهــاى آن شـدهانــد را بـراى افـراد هـيش ديـابتى فـراهم آورد. از

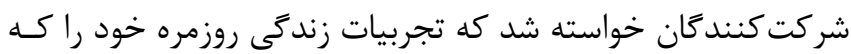

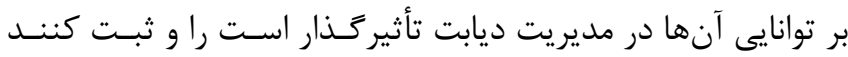

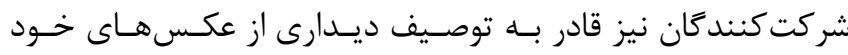

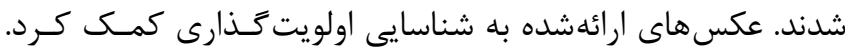

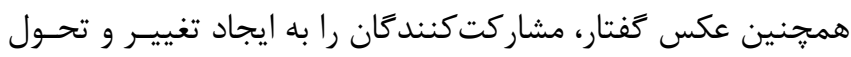
در جامعه خود ترغيب نمود. يكى از اين عوامل، ايجاد كانال ارتباطى كمانى بين مردم و سياست كذاران است كه امكان كفتتكو با سياست كَذاراران

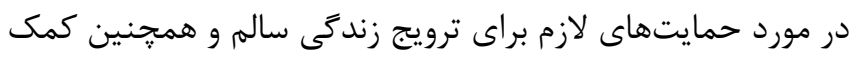

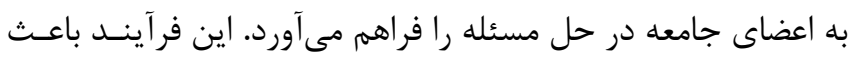
شد، علاقه به برقرارى ارتباط آكاهىبخش جمعى توسعهيافته و ميل

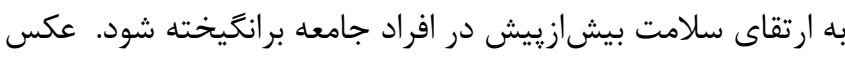

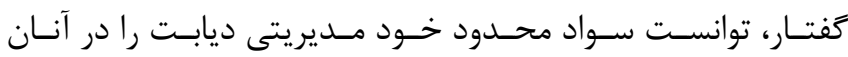
يشتيبان نمايد. در شهرستان هويزه، عكسها وجود مشكلات در مورد مسائل مربوط

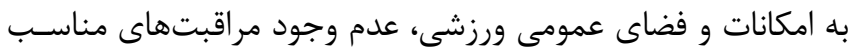

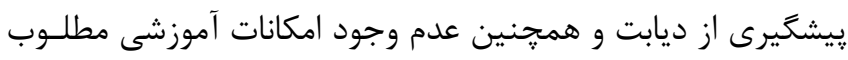

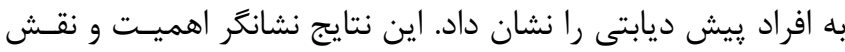

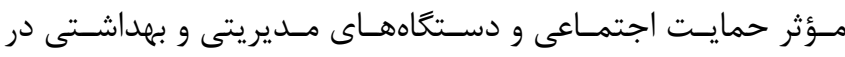
موضوعات مرتبط با سلامت به شمار مىرود.

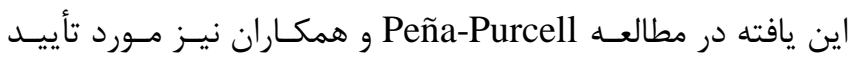

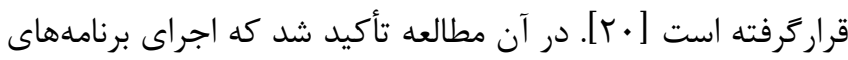

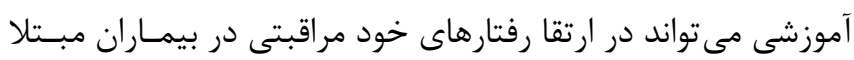

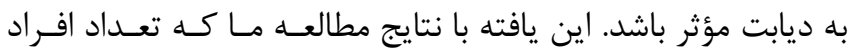

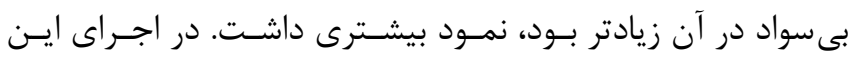

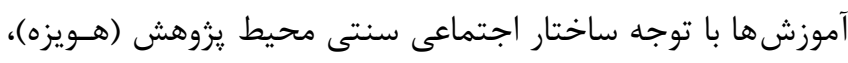

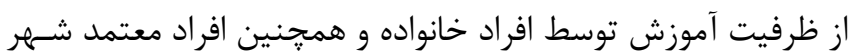

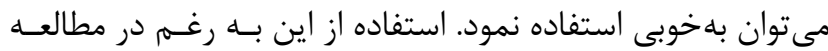

Brown and Hanis

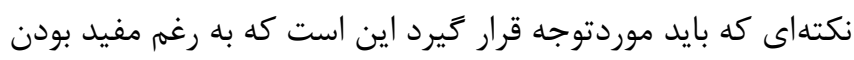

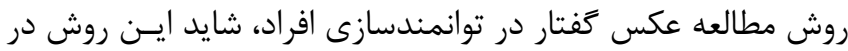

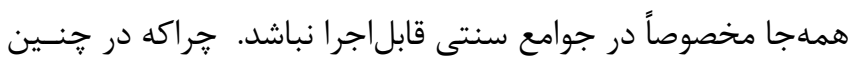

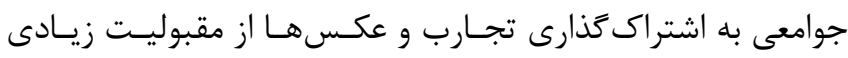

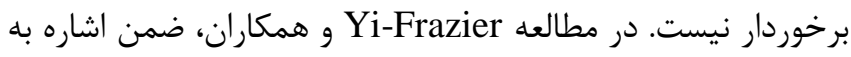

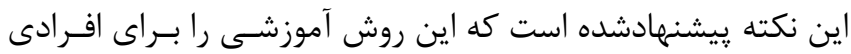

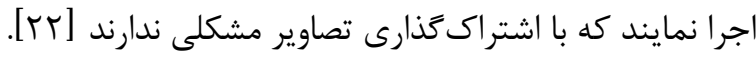




\section{منابع}

1. Kharroubi AT, Darwish HM. Diabetes mellitus: The epidemic of the century. World journal of diabetes. 2015;6:850

2. Hostalek Ulrike. Global epidemiology of prediabetes-present and future perspectives. Clinical diabetes and endocrinology 2019;5 :1-5

3. Shen Jia, et al. A multiethnic study of pre-diabetes and diabetes in LMIC. Global heart 2016;11:61-70

4. Shaw Jonathan E, Sicree Richard A, Zimmet Paul Z. Global estimates of the prevalence of diabetes for 2010 and 2030. Diabetes Research and Clinical Practice 2010;87:4-14

5 Esteghamati Alireza, et al. Diabetes in Iran: prospective analysis from first nationwide diabetes report of National Program for Prevention and Control of Diabetes (NPPCD-2016). Scientific Reports, 2017:7:1-10

6. Vijayakumar Gadadharan, et al. Incidence of type 2 diabetes mellitus and prediabetes in Kerala, India: results from a 10-year prospective cohort. BMC Public Health 2019;19:140

7. Luo Zhen, Fabre Guilhem, Rodwin Victor G. Meeting the challenge of diabetes in China. International Journal of Health Policy and Management 2020;9: 47

8. Mirzaei Masoud, et al. Epidemiology of diabetes mellitus, pre-diabetes, undiagnosed and uncontrolled diabetes in Central Iran: results from Yazd health study. BMC Public Health 2020;20:166

9. WU Yanling, et al. Risk factors contributing to type 2 diabetes and recent advances in the treatment and prevention. International Journal of Medical Sciences. 2014;11:1185

10. Tuso Phillip. Prediabetes and lifestyle modification: time to prevent a preventable disease. The Permanente Journal 2014;18:88

11. Sutton-Brown, Camille A. Photovoice: A methodological guide. Photography and Culture. 2014;7:169-185

12. Baker TA, Wang CC. Photovoice: Use of a participatory action research method to explore the chronic pain experience in older adults. Qualitative Health Research 2006;16:1405-13
13. Wang C, Burris MA. Photovoice: Concept, methodology, and use for participatory needs assessment. Health Education and Behavior 1997;24:369-87

14. Komaie Goldie, et al. Photovoice as a pedagogical tool to increase research literacy among community members. Pedagogy in Health Promotion 2018;4:108-14 15. Yankeelov Pamela A., et al. "Another Day in Paradise" A Photovoice Journey of Rural Older Adults Living with Diabetes. Journal of Applied Gerontology 2015;34:199-218

16. Castleden Heather, et al. Modifying Photovoice for community-based participatory Indigenous research. Social Science and Medicine 2008;66) :1393-1405

17. Wallerstein Nina, Duran Bonnie. Communitybased participatory research contributions to intervention research: the intersection of science and practice to improve health equity. American Journal of Public Health 2010;100: S40-S46

18. Carter Jane, et al. Learning about women's empowerment in the context of development projects: do the figures tell us enough? Gender and Development 2014;22:327-49

19. Baker Tamara A, Wang Caroline C. Photovoice: Use of a participatory action research method to explore the chronic pain experience in older adults. Qualitative Health Research 2006;16:1405-1413

20. Peña-Purcell Ninfa $C$, Cutchen Lauren, Mccoy Traechel. "You've Got to Love Yourself": Photovoice Stories from African Americans and Hispanic/Latinos Living with Diabetes. Journal of Transcultural Nursing 2018;29:229-239

21. Brown Sharon A, Hanis Craig L. Lessons learned from 20 years of diabetes self-management research with Mexican Americans in Starr County, Texas. The Diabetes Educator 2014;40:476-487

22. Yi-Frazier Joyce P., et al. Using Instagram as a modified application of photovoice for storytelling and sharing in adolescents with type 1 diabetes. Qualitative Health Research 2015;25:1372-1382 